\title{
A MEMÓRIA DA ÁGUA: INFORMAÇÕES ENERGOVIBRACIONAIS
}

\author{
Mayara Cossolino Martelo ${ }^{1}$ \\ Marcus Vinicius Cordeiro Forte ${ }^{2}$ \\ Elias Abrão Neto ${ }^{3}$
}

\section{RESUMO}

O presente estudo trata-se de uma revisão bibliográfica acerca do tema "A Capacidade da Água de Armazenar Memória". Baseia-se em dois trabalhos científicos que descrevem e comprovam tal capacidade: Stagnaro (2011) e Montagnier (2011). O foco do atual trabalho é adentrar nas bases teóricas apresentadas por ambos os autores, esclarecendo assim o funcionamento da capacidade de retenção e transmissão de memória pela água. São também citados alguns estudos empíricos dos autores que corroboram a hipótese de que a água retém e transmite informação, trazendo assim também elementos práticos para o estudo de revisão. Através da soma das informações apresentadas foi possível chegar a uma compreensão mais profunda do mecanismo responsável por essa capacidade, esclarecendo e explicando o princípio que rege tratamentos dentro da Naturopatia como florais e homeopatia.

Palavras-chaves: Memória da Água. Energia-informação. Florais. Homeopatia.

\footnotetext{
${ }^{1}$ Graduada em Naturopatia pela Unilogos

${ }^{2}$ Graduado em Naturopatia pela Humaniversidade Holística

${ }^{3}$ Mestre em Fitoterapia pela Unilogos
} 


\section{INTRODUÇÃO}

Este trabalho diz respeito a um dos princípios da água recém estudados pela Ciência. É uma das maiores bases de terapias dentro da Naturopatia como: Florais, Homeopatia, etc. Este princípio diz respeito à capacidade da água de reter e transmitir informação: a água se comporta como receptor, recebendo e armazenando determinada informação vibracional; e então se porta como emissor, transmitindo a informação armazenada.

Unindo a Biologia com a Física Quântica, este é um assunto que traz implicações essenciais para o entendimento da realidade ao nosso redor, visto que o corpo humano é em torno de $80 \%$ composto de água (Stagnaro, 2011) e tem função vital para os sistemas biológicos de manutenção da vida. O princípio a ser estudado aqui traz grandes implicações sobre como o corpo humano se comunica biologicamente para manter sua estrutura e funcionamento.

Serão expostos os estudos prévios sobre este tema, apresentando possíveis implicações, de modo a trazer uma nova visão sobre o assunto: água e funcionamento quântico do corpo humano. Desta forma, poderá ser compreendido como é de grande importância que este assunto seja mais exposto e estudado por futuras pesquisas. Serão delineados assuntos como: Energia-Informação versus Energia-Vibração, o papel quântico que o DNA realiza para sinalizar e guiar o funcionamento biológico, estudos e teorias expostas anteriormente por outros autores, que são cruciais para o presente tema. Serão apresentados dados teóricos e citados estudos clínicos sobre o assunto, de modo a corroborar e demonstrar o princípio da água de armazenamento e emissão de informações.

\section{BASES TEÓRICAS}

Os estudos de Stagnaro (2011) e os experimentos de Montagnier (2011) apresentam resultados testados e teorias complementares sobre a capacidade da água de reter e transmitir informações.

Em seu artigo "A New Way of Therapy based on Water MemoryInformation: The Quantum Biophysical Approach", Stagnaro (2011) trabalha com 
o conceito Informação-Memória da água. Stagnaro (2011) define o estágio "Memória" quando a água se comporta como receptor, recebendo frequências de ondas e as armazenando; e "Informação" o momento em que a água age como transmissor, emitindo as frequências de ondas anteriormente armazenadas.

A base teórica dos estudos de Stagnaro (2011) considera como um dos pilares centrais a Semiótica Biofísica Quântica ( $\mathrm{SBQ}$, em inglês QBS), que estuda o funcionamento quântico dos sistemas biológicos. O autor utiliza ferramentas SBQ para demonstrar em estudos clínicos sua teoria da "Informação-Memória da Água", a partir de sistemas controlados onde a água se submete a energização a nível quântico (STAGNARO 2011).

\subsection{Os princípios da Semiótica Biofísica Quântica}

A SBQ considera que o funcionamento biológico do corpo humano emite sinais que seguem as leis do caos determinístico (LORENZ 1963, RUELLE 1991, CRAMER 1994, STAGNARO et al. 1996). Estes sinais podem ser medidos estatisticamente para fins diagnósticos. Stagnaro (2011) comenta e Montagnier (2011) demonstra em seus estudos que o DNA tem função de emitir sinais (informação-energia) de comunicação para todos os sistemas biológicos, gerindo o funcionamento dos bio-sistemas a nível quântico.

A SBQ leva em consideração a Química, Biologia, Genética, Neurociência, Teoria do Caos e Física Quântica. Assim, defende e desenvolve métodos para que possam ser medidos os sinais que o corpo humano emite quando estimulado, e consegue obter os dados para conclusão de informações qualitativas como: se aquele corpo se encontra em estado de saúde ou estado de doença, as pré-disposições que a genética de uma pessoa traz para determinadas doenças, e mecanismos para tratamento terapêutico preventivo destas pré-disposições.

O princípio quântico que a SBQ leva em consideração é de que um sistema biológico pode ser mensurado por uma dimensão fractal; ou seja, o 
sistema biológico local é sempre acompanhado por uma realidade não local, mas simultânea, sincrônica e paralela, que pode trazer dados e informações sobre aquele determinado sistema biológico (corpo humano em funcionamento) (STAGNARO 2011). Através destes dados, pode ser medido e avaliado patologias potenciais, tendências para desenvolver doenças ou estados crônicos.

Um dos destaques SBQ para o presente trabalho é a capacidade de detectar uma existência potencial de doenças como câncer (STAGNARO, 2004a), diabetes (STAGNARO, 2002; CARAMEL, 2010c), hipertensão, disfunções cerebrais (STAGNARO, 1986; CARAMEL, et al. 2011d), problemas cardíacos (STAGNARO, et al., 1997), desde o nascimento do indivíduo. Esta detecção é nomeada de Risco Real congênito (RR), e é possível ser avaliada através da citopatia mitocondrial (condição dolorosa da célula, que Stagnaro chama de CAEMH) (STAGNARO, 1985; CARAMEL et al., 2010a). Esta condição pode ser avaliada desde o nascimento através do DNA mitocondrial provindo da mãe. Assim, através destas análises e detecções, chega-se à chamada constituição SBQ, que é o conjunto de dados que apresentará ou não o Risco Real congênito.

No presente trabalho, isso se relaciona com o tema da capacidade de memória da água a partir da possibilidade de que o RR é nada mais do que uma informação de uma doença armazenada na água do corpo da pessoa. Esta informação, advinda do DNA mitocondrial, transmite para o funcionamento biológico que aquela possibilidade existe, e está ali armazenada, até o momento de manifestação do $R R$, em que aquela informação começa a guiar todo o funcionamento biológico para um estado de doença. Isso será explicado mais detalhadamente nos tópicos sobre Energia Informação, Energia Vibração e Energia Matéria.

\subsection{Investigação SBQ}

A suposição central da SBQ é de que o genoma afeta principalmente o parênquima e os microvasos. Para que se entenda o comportamento fisiológico 
ou patológico do parênquima, é preciso que se investigue os microvasos, cujas flutuações proporcionam informações quantitativas e qualitativas sobre a dinâmica da microcirculação de um ponto de vista estrutural e funcional. As falhas na microcirculação podem indicar doenças ou patologias presentes nos parênquimas das células correlacionadas aos microvasos. Estas indicações de funcionamento biológicos se devem a alterações genéticas do DNA mitocondrial, e nos demonstram a chamada citopatia mitocondrial (CAEMH).

A CAEMH expõe as diferentes constituições SBQ (STAGNARO, 2007a), assim pode-se detectar RR, potencialidades de doenças que ainda não se manifestaram, para que possam ser tratadas preventivamente. $O$ fator do tratamento preventivo também é baseado nas constituições $S B Q$, que são avaliadas para detectar se aquele $R R$ ainda persiste ou já está sendo extinguido (STAGNARO, 2011).

É interessante ressaltar que tanto o diagnóstico quanto o tratamento, aqui, é feito a nível de informações presentes nos sinais emitidos pelo sistema biológico (constituição SBQ). O tratamento é direcionado para a informação que se manifestará como sintoma, diferente da abordagem tradicional que trata os sintomas de uma doença já manifestada. O principal ponto aqui é transformar a informação da potencial doença de volta para uma informação de saúde.

Stagnaro (2011) apresenta uma sequência de evolução para a manifestação de uma informação em doença, dando-se como: 1) alteração do DNA mitrocondrial; 2) CAEMH; 3) constituição SBQ; 4) RR (até o item 4, ainda estamos em estado pré-clínico, ou seja, a doença ainda não se manifestou); 5) patologia; 6) cronicidade. Ou seja, inicialmente a alteração ou informação do DNA mitocondrial acontece, gerando uma CAEMH que gera uma constituição $S B Q$, e apresenta um RR, um risco, uma pré-disposição a uma doença. A partir do RR, manifesta-se a patologia, ou seja, a doença é expressa no corpo a partir dos sintomas, e então parte para a cronicidade, ou seja, a doença se torna parte da configuração daquele sistema biológico.

Os estudos clínicos de Stagnaro (2011) adentram mais profundamente nas questões de microvasos, estados de stress do parênquima, respiração mitocondrial, reserva funcional microcirculatória (RFM) e fatores como diminuição do nível de oxigenação dos tecidos. No presente trabalho será 
estudado mais a teoria a partir das conclusões e implicações destes estudos clínicos, não aprofundando na descrição dos experimentos em si.

Resumidamente, a importância dos microvasos para as medições SBQ, é de que eles se

"comportam como sistemas dissipativos longe do equilíbrio, e, se propriamente estimulados, eles nos levam a comportamentos locais que nos dão informações qualitativas e quantitativas importantes sobre o estado de saúde funcional e estrutural, e indiretamente fornecem informação sobre seu parênquima relativo." (STAGNARO; CARAMEL, 2011)

\subsection{Teoria de Bohm e as variáveis de energia}

David Bohm é outro autor de uma das principais bases teóricas deste trabalho. Esta base teórica diz respeito ao potencial quântico ou potencial informacional (PQ). O autor afirma que esse potencial age de modo a guiar o movimento das partículas variáveis escondidas. É assim uma nova forma de se interpretar a teoria quântica do Gato de Schrödinger como mencionado por Stagnaro (2011).

Bohm (2011) descreve o potencial quântico a partir da metáfora do navio: um navio que navega por piloto automático, guiado por ondas de rádio. O efeito da onda de rádio é independente de sua força ou tamanho, depende apenas de sua forma. O navio se move com sua própria energia, mas a simples informação da onda de rádio é captada e usada para direcionar uma energia maior, a própria. Se o navio tivesse um piloto, mas o ambiente estivesse nublado, o piloto não conseguiria chegar ao porto sem o auxílio de seu radar (ondas de rádio). Ou seja, uma pequena energia (ondas de rádio), porém rica em informação, dirige todo o direcionamento do navio.

Traduzindo para o presente trabalho, uma pequena energia (informação) tem a capacidade de direcionar todo um sistema de energia maior, bastando apenas sua qualidade, não quantidade. A qualidade da informação direciona toda a energia disponível em quantidade.

A partir desta teoria quântica de Bohm (2011), Stagnaro (2011) apresenta em seu estudo os seguintes conceitos, aplicados então aos 
biossistemas: Energia-Informação, Energia Vibração, Matéria-Energia. De maneira simplificada, a Energia-Informação é a onda de rádio que guia todo 0 navio, Energia-Vibração é a variável quantitativa, ou seja, a quantidade de energia maior que age para sustentar o funcionamento do navio e tornar possível que ele se mova; Matéria-Energia é o movimento realizado, tanto como também o navio em si.

Como os sistemas biológicos são baseados em um sistema de comunicação, podemos afirmar que o DNA/RNA é não apenas um reservatório de informação genética, mas também um sistema dinâmico de EnergiaInformação (MANZELLI 2007) capaz de transmitir e receber sinais quânticos biofísicos para as células (especificamente suas proteínas). Assim, o DNA pode ser visto como a antena central do sistema biológico humano, que gerencia e direciona todo o corpo e seu funcionamento biológico (o navio, VibraçãoEnergia) através informações não locais denominadas "sinais quânticos de gene". Assim, o DNA deve ser analisado não só em seu comportamento químico e biológico, mas também em seu aspecto quântico, não local, que recebe e emite sinais, gerenciando desde funções biológicas até mesmo questões mentais e emocionais. O DNA é o guia e direcionador do ser humano em seus diversos aspectos, assim como a onda de rádio é o guia do navio em alto mar.

É extremamente importante o estudo das questões quânticas do DNA para compreender a vida humana e a existência como um todo. A SBQ já inicia estes estudos, mas ainda há muito mais a se aprofundar. Unindo Física Quântica, Biologia e Química, conseguimos trazer até mesmo compreensões científicas para questões hoje abordadas somente na área da Espiritualidade.

Uma das questões a serem analisadas muito profundamente é se o nosso DNA se porta como antena a nível quântico e biológico, levando em consideração as realidades não locais, simultâneas e paralelas já citadas anteriormente, que nos influenciam, influenciam nosso equilíbrio biológico, quais são as outras margens destas realidades? Elas seriam acessíveis além das métricas já utilizadas pela SBQ? Teriam os seres humanos uma plataforma de informação base que emite a informação quântica do que é ser um humano em oposição a um cachorro? Para que então a partir desta informação, a VibraçãoEnergia seja guiada e se transforme Matéria-Energia em seus diversos aspectos. 
E caso esta plataforma de informação base exista e seja identificada cientificamente pela física quântica ou SBQ, onde estaria localizada? Em que realidade não local? Quais as variáveis envolvidas para que ela se mantenha? Ela realmente se mantém intacta, ou sofre alterações e isso é captado pelo DNA humano e reproduzido nos sistemas biológicos humanos? Como esta possível plataforma de informação base foi organizada? Quais os fatores quânticos ainda não identificados estão envolvidos? Como isso se relaciona com o ser humano na atualidade? Quais são as implicações destas possíveis futuras respostas para a saúde humana, tanto biológica quanto psicológica, no que diz respeito à saúde da concepção de sua própria existência? Estas possíveis respostas poderiam revolucionar totalmente o modo como enxergamos e percebemos o mundo, e também como nos relacionamos uns com os outros?

Nota-se que este é um campo muito rico para descobertas, estudos, discussões, e tem um enorme potencial de ressignificar o conceito do que é ser humano e estar vivo dentro um sistema social.

Retomando a teoria das variáveis Energia-Informação, Energia-Vibração e Matéria-Energia, Stagnaro (2011) expõe que a soma de todas as transformações de energia, ou seja, a soma destas variáveis, sempre corresponde a uma constante igual a zero. Ou seja: $\Delta(\mathrm{IE}+\mathrm{VE}+\mathrm{ME})=0$. Assim se dá o equilíbrio destas variáveis, e é de acordo com esta constante que se mantém o equilíbrio dos sistemas biológicos. $\mathrm{O}$ autor cita um exemplo de que se existe um quadro de acidose tecidular (sinal de uma potencial patologia), a Matéria-Energia aumenta, paralelo à diminuição da Energia-Vibração e da Energia-Informação na mesma proporção. Esta equação descreve como se dá a manifestação de um RR em uma doença crônica ou aguda.

Stagnaro (2011) destaca também em seu artigo que a EnergiaInformação é uma energia tênue e catalisadora, rica em informação, que direciona local e globalmente todos os processos biológicos e todos os sistemas conectados. 


\subsection{Identidade fotônica e vibracional}

Stagnaro (2011) expõe que as células vivas são compostas de 70\% a $90 \%$ de água. Cita que elas emitem biofótons não vistos a olho nu, mas que podem ser medidos por equipamentos especiais ou avaliados como modificações vistas nas funções dos sistemas biológicos.

Já que as células se comunicam por meio de explosões de energia tanto a nível de neuropeptídeos (presentes em todas as partes do corpo) quanto nas faixas eletromagnéticas abaixo do espectro de luz visível, pode-se dizer que essas explosões, essas emissões, controlam processos vitais do corpo humano. É citado no trabalho de Stagnaro (2011) que as células cancerosas emitem fótons de energia diferentes de uma célula saudável. Ou seja, existe um padrão de fótons para uma célula cancerosa, e um padrão diferente de fótons para uma célula saudável. Aqui é possível evidenciar que existe um padrão, uma identidade fotônica de emissão para uma doença específica, e existe também uma identidade fotônica determinada que sinaliza uma célula saudável. Tais emissões fotônicas repercutem nos diferentes padrões biológicos de microcirculação, que podem assim então serem captados e retransmitidos através de aparatos quânticos. Os estudos clínicos de Stagnaro (2011) relacionados a este tema, em sua maioria, são baseados nestes preceitos da microcirculação, utilizando um aparato quântico com este propósito. O autor não descreve com profundidade sobre o aparato, porém disponibiliza vias de contato para mais informações.

Como será descrito posteriormente, Montagnier (2011) apresenta um experimento que demonstra a capacidade do DNA de transmitir informações genéticas (Energia-Informação) para a água através de ondas eletromagnéticas. Neste estudo, é confirmada a capacidade da água de reproduzir as informações do DNA através de suas nanoestruturas e ressonância eletromagnética. Ou seja, é confirmado a teoria de que a água é capaz de receber informação e então transmiti-la.

Para compreender o funcionamento desta capacidade da água, é importante levar em consideração o conceito de identidade fotônica já mencionado, e também o conceito de identidade vibracional. Estudos recentes 
(GERMANOV et al., 2011) demonstram que substâncias químicas de natureza orgânica e não orgânicas, tanto quanto elementos biológicos, emitem ondas, ou seja, têm uma identidade vibracional. Assim, o padrão vibracional de cada substância (orgânica ou não orgânica) é específico, e quando analisado o padrão vibratório dos elementos biológicos, encontram-se frequências correspondentes às substâncias que os compõem, ou seja, encontram-se frequências de espectros que representam a soma dos elementos. Desta forma, os fluidos biológicos do corpo humano (sangue, urina, etc.) emitem sinais que caracterizam o estado do corpo. Ou seja, o corpo humano pode ser avaliado por seu estado a nível vibratório através da análise de seus fluidos.

\subsection{Estrutura teórica de Montagnier}

Montagnier (2011) apresenta uma explicação do funcionamento da capacidade da água de reter e transmitir memória. Para compreendermos, é preciso compreender que se trata de uma teoria não linear, que descreve um complexo de processos também não lineares.

O autor parte do ponto de que as moléculas da água líquida não são ligadas apenas por interações estáticas (ligações de hidrogênio e interações dipolo-dipolo), mas também por um campo de radiação eletromagnética dependente de tempo. Ou seja, as ligações de hidrogênio são consequentes da condensação de moléculas induzidas por este campo de radiação.

O autor cita que uma combinação de moléculas interage com o campo de radiação eletromagnética (determinados sobre um patamar de densidade e acima de uma temperatura crítica, ou seja, dentro de variáveis específicas), e assim adquire um estado de energia mínima, não trivial, diferente da energia mínima padrão (em que as oscilações das moléculas não se correlacionam e o campo eletromagnético está em constante desaparecimento). Este novo estado de energia mínima descreve a configuração de um sistema em que as moléculas se encontram dentro de uma região específica, que o autor chama de Domínio de Coerência (DC). Dentro do DC as moléculas oscilam em uníssono, ou seja, de modo correlacionado, em um campo eletromagnético "preso" dentro do DC. 
Desta forma, o tamanho do DC é o comprimento de onda do campo eletromagnético preso dentro do DC. Dá-se, assim, uma oscilação coerente e coletiva entre as moléculas que compõem o DC. Esta oscilação coerente ocorre a partir da oscilação padrão da molécula, e um novo estado de oscilação (estado excitado). O estado excitado de oscilação da molécula é, em volume, maior do que o estado padrão. Ou seja, dentro do DC existe um patamar base de oscilação/vibração da molécula, e um patamar de oscilação/vibração excitado, que é mais alto do que o patamar base. Assim se dá os estados de oscilação/vibração dentro do DC.

O autor cita que, de acordo com o mecanismo de Anderson-HiggsKibble, o fóton do campo eletromagnético preso dentro do DC adquire uma massa imaginária, e então se torna incapaz de sair do DC. Desta forma, este campo "autoaprisionador" do DC possui um padrão de energia consistente, porém finito. Por causa disso, a frequência do campo eletromagnético preso dentro do DC se torna menor do que a frequência o campo livre (externo ao DC), apesar de ter o mesmo comprimento de onda.

É possível descrever este embasamento teórico com a metáfora da bolha de sabão: existem bolhas de sabão flutuando no ar. A superfície da bolha se traduz como o DC, o campo eletromagnético preso dentro do DC é o ar dentro da bolha, e o campo eletromagnético livre é o ar livre onde a bolha flutua. Dentro da bolha existe ar, fora também. Porém o ar de dentro da bolha, apesar de ser o mesmo, não se comunica com o de fora, ele está "empacotado", autoaprisionado dentro da superfície da bolha, que pode ser medida pelo próprio volume do ar empacotado.

É citado que este mecanismo funciona para todos os líquidos, porém a água possui uma peculiaridade: a oscilação coerente ocorre entre um patamar base e um estado excitado por volta de 12,06eV, logo antes do patamar de ionização $(12,60 \mathrm{eV})$. Neste caso, dentro do DC existe uma combinação de elétrons sem coerência harmônica na eletrosfera que são capazes de receber energia exterior fornecida e transformá-la em oscilações coerentes. Nessas oscilações, a entropia dá-se muito menor do que a entropia da energia externa fornecida. Ou seja, dentro do DC que se faz na água a energia perde-se com menos facilidade do que a energia externa. 
Ou seja, os elétrons livres fora do DC e elétrons não livres dentro do DC criam um cenário magnético de incompatibilidade harmônica da última camada da eletrosfera, onde existe um fluxo coerente em relação aos elétrons dentro do DC. Por transferência de carga iônica, através do aumento da taxa de eletrovolts de 12,06 para 12,60, que faz com que os elétrons dentro do DC venham a ter também uma coerência no que se refere à oscilação. Com isso, tem-se uma vantagem peculiar da molécula da água no $\mathrm{DC}$, onde a coerência de onda conquistada pelos elétrons dentro do DC ganha a singularidade de perder menos energia entrópica do que ocorre fora do DC. Com isso, o DC ganha uma característica e qualidade de manter níveis de uma ionização e preservação energética de melhor e maior quantidade do que a molécula simplesmente solta, fora do DC.

\subsection{Temperatura e funcionamento de um DC}

Montaigner (2011) expõe em seu estudo alguns fatores críticos para que um DC seja formado e descreve também como estes fatores determinam a transferência da energia/informação armazenada neste DC. Antes de discorrer sobre estes fatores, é válido citar que um DC (a bolha que contém energia armazenada) pode ser dita aqui como um campo (domínio complexo) formado nas moléculas de água, que armazenam com estabilidade um tipo de energia fornecida. Levando em consideração o termo já explicado de EnergiaInformação, levamos em consideração aqui que esta energia armazenada no DC age como informacional, ou seja, é na verdade uma informação armazenada nesta "bolha".

É descrito no estudo de Montagnier (2011) que um dos fatores determinantes para manter a formação de um DC é a variação de temperatura. O autor cita que a variação de temperatura (ruído térmico), que dá o movimento às moléculas de água, dá origem a campos de coerência e campos de não coerência, agrupados por temperatura. A água pode parecer homogênea, mas na verdade quando analisada mais detalhadamente ela possui várias oscilações de energia e temperatura, e está toda em movimento/transformação a nível eletrônico. Os campos coerentes são menos vulneráveis a oscilações de 
temperatura, pois em agrupamento as moléculas se mantêm em estabilidade eletrônica. Agrupadas por atração eletrodinâmica, as moléculas (o autor explica como isso se dá mais detalhadamente em seu estudo: a competição entre o campo eletrodinâmico e o ruído térmico dão origem a um campo eletromagnético) compõem um DC que armazena energia externa (fornecida). Assim, são formados vórtices coerentes. Dentro de um DC, dá-se uma soma de vários vórtices coerentes, que se tornam uma disposição duradoura. Esta soma de vórtices dentro do DC ativa uma nova resposta e nível de elétron, ou seja, existe uma mudança de frequência eletrônica.

Resumindo e esclarecendo este funcionamento, antes da formação de um DC havia um sistema não coerente perdendo energia; com a atração do campo eletromagnético formado pelo DC, a energia que antes era perdida é unificada e armazenada. O que mantém a estabilidade deste campo de armazenamento é a nova frequência do elétron, que não deixa que a energia escape do $D C$. $O$ elétron sofre alteração de frequência, ângulo orbital e velocidade, e este conjunto de alterações formam um campo eletromagnético de maior coesão, não deixando o DC se desfazer.

\subsection{Transferência de energia informação}

Montagnier (2011) expõe que um DC, ao entrar em contato com uma biomolécula, transfere a energia (informação) armazenada para a molécula em questão. Ele ressalta no estudo que esta molécula, para receber a energia (informação) armazenada no DC, precisa ser não aquosa e orgânica, e entrar em contato com o DC. Caso seja uma molécula aquosa que entre em contato, ela é atraída para fazer parte do DC. Ou seja, a "molécula visitante" aquosa se torna "molécula membro". Assim se dá a replicação dos DCs.

O autor cita também que, devido ao equilíbrio eletrodinâmico de um DC, o próprio DC consegue repor a frequência iônica das membranas celulares (as quais ele entra em contato), que anteriormente haviam entrado em desorganização harmônica pela perda de íons da membrana. O DC atua na eletrodinâmica para atrair o equilíbrio correto dos íons na célula. Ou seja, é a Energia-Informação atuando e orientando eletrodinamicamente o funcionamento 
de uma célula. Isto é dependente, porém, do tipo de energia informação armazenado dentro do DC.

Aqui, podemos ressaltar que este vem a ser o mecanismo pelo qual os processos de doença são curados por medicamentos: homeopáticos, florais, e inclusive também o efeito dos benzimentos com água; diz respeito à frequência de onda (que gera uma energia informação) armazenada como vórtices dentro de um DC da água em questão (benzida, do floral ou da homeopatia), que ao entrar em contato com o corpo humano (biomolécula, células vivas) reordenam o funcionamento eletrodinâmico de volta para uma informação de saúde. O autor cita que o DC atua a nível de iônico (já que mexe com a eletrodinâmica - nível de elétron).

\subsection{A nível de ressonância}

O autor coloca também como um fator determinante para a manutenção de um nível positivo coerente do DC uma frequência de até $100 \mathrm{~Hz}$. Ele cita que este campo pode ser produzido artificialmente, por fatores ambientais (por exemplo Ressonância Schumann), ou até mesmo gerado pelo sistema nervoso.

Ou seja, o próprio sistema nervoso do corpo humano consegue gerar um campo ideal para um excelente funcionamento dos DCs da água. É válido ressaltar aqui a importância, então, de processos meditativos que fazem com que o sistema nervoso induza ondas cerebrais específicas. Aqui podemos incluir: meditações, Mindfullness, Reiki, MagnifiedHealing, Cromoterapia, Terapia com som, Mantras, Cristaloterapia, e também muitos outros tratamentos dentro da Naturopatia que colocam o indivíduo em estado de relaxamento.

Stagnaro (2011) menciona também que, se a frequência eletromagnética não for pareável com a Ressonância Schumann, é possível que a função biológica seja inibida. Ou seja, a Ressonância Schumann é o campo geomagnético da Terra, que está em consonância com os mecanismos de funcionamento do DC da água (inclusive da água do corpo humano) e tem papel crucial para a manutenção da vida biológica. Caso uma frequência eletromagnética ultrapasse dessa ressonância ou das ressonâncias de equilíbrio do DC, as funções biológicas começam a ser inibidas, ou seja, inicia-se um 
processo de morte celular/ doença. Aqui podemos ressaltar a CAEMH citada no início deste estudo. Resumindo, para mantermos uma saúde biológica e um equilíbrio harmônico dos DCs da água do nosso corpo, é necessário que estejamos em consonância com o campo vibracional natural do planeta em que habitamos. Os níveis eletromagnéticos onde dissoamos dos campos naturais até um certo patamar, são os níveis específicos onde desenvolvemos energiainformação de doença na nossa composição eletrodinâmica biológica, que parte então para a manifestação a nível físico, como já explicado também neste estudo.

\subsection{A atuação de DCs no DNA}

Stagnaro (2011) demonstra que esta atuação dos DCs da água foi capaz de armazenar a energia informação de um código genético (DNA) que foi replicado com uma taxa de $98 \%$ de exatidão em relação ao original, apenas pela atuação da informação armazenada na água. Ou seja, um DNA "desmontado" ("moléculas ingredientes") foi formado a partir apenas das informações contidas na água, informações que carregavam as sequências do DNA em questão (do experimento).

Este fato confirma a tese do autor explicada neste estudo sobre 0 armazenamento de memória/informação na água (quando no experimento transferiu-se a informação da sequência genética para a água), e da capacidade de a água transmitir informações (quando conseguiu-se replicar 98\% do DNA original apenas com a informação contida na água, quando esta entrou em contato com as moléculas "ingredientes" para se formar um DNA). Confirma também a teoria do autor de que é necessário que o DC entre em contato com uma molécula orgânica para transferir as informações. A partir desta transferência, as próprias moléculas se agruparam de uma maneira específicas. É a Energia-Informação "guiando" a Energia-Vibração desencadeando na matéria (o novo DNA replicado formado). 


\section{CONCLUSÃO}

Os materiais estudados no presente trabalho confirmam e demonstram a capacidade de a água atuar como veículo receptor, armazenador e transmissor de informação, ou seja, é descrito no presente estudo a confirmação de como se dá a capacidade de a água armazenar e transmitir memória (informação). Assim, notamos também que a água é um fator importante na comunicação e gerenciamento da biologia a partir do DNA, ou seja, essa capacidade da água é essencial para a manutenção do funcionamento de um sistema biológico.

Estudamos no presente estudo este fator e nos deparamos com uma questão que vale a pena ser ressaltada: a saúde do corpo é ordenada a partir da uma informação, uma vez que também estudamos que todos os sistemas biológicos possuem uma identidade vibracional e fornecem uma somatória que nos informa estados de doença ou estados de saúde. É de grande valia para a Naturopatia este estudo, pois mostra a importância de tratar uma doença a nível de informação, não apenas a nível de sintomas. Ou seja, aqui vemos a importância de técnicas de Naturopatia que trabalham com o tratamento de informação vibracional (Reiki, MagnifiedHealing, ThetaHealing, Florais, Homeopatia, Cromoterapia etc.), para que os sistemas biológicos se movam para um estado de saúde, evitando também recaídas tão comuns em tratamentos alopáticos tradicionais.

Explicitamos também como ocorre a nível eletromagnético 0 armazenamento e a transmissão de informações pela água, e então nos deparamos com outra questão de grande importância para as áreas de atuação da Naturopatia: a atuação positiva dos campos de informação da água se dá com o pareamento de ondas de até $100 \mathrm{~Hz}$. É citado que o sistema nervoso é capaz de produzis tais ondas, também como o campo geomagnético da Terra. Ressaltamos então a importância de técnicas da Naturopatia que colocam o indivíduo em estados de tranquilidade, relaxamento e meditação como Reiki, Cromoterapia, Mindfullness, Acupuntura, etc. Quando o indivíduo se encontra neste estado de relaxamento, seu sistema nervoso propicia condições ideais para que a água de seu corpo comece a atuar a nível de campos de informação 
de maneira positiva, e abre-se uma janela para restauração dos estados de saúde onde anteriormente existiam estados de doença.

É possível que este compilado de estudos explique também as "curas milagrosas" através do benzimentos e orações, que os médicos atuais não são capazes de explicar. Este é um compilado de estudos profundos sobre propriedades da água e do DNA que abre um leque para estudos inovadores que podem revolucionar os campos da ciência e da saúde atuais. O compilado de estudos citados traz a importância de valorizar mais uma medicina preventiva que trate o paciente a nível das informações que ele traz em seu DNA, para que não precise sofrer com sintomas físicos que são etapas de manifestação posteriores (como descrito neste trabalho), e também para que a cura seja efetiva e não acarrete frequentes recaídas.

No presente trabalho concluímos a importância de dois fatores que atuam em consonância: a informação (memória) e a água. Se mudarmos nossa visão e abordagem para um tratamento, não para sanar os sintomas, mas sim para harmonizar as informações ali apresentadas, é possível que se chegue a novos patamares de sucesso terapêutico e bem-estar dos pacientes. E a água, como já explicitado, é um dos melhores veículos para tal, uma vez que possui as propriedades citadas e também se encontra em grande quantidade na composição do corpo humano.

Por fim, ressaltamos a importância da água para o corpo humano para a manutenção da vida em um sistema biológico e para o armazenamento e transmissão de informação (memória). Citamos aqui a frase de Jesus em "O Evangelho Essênio da Paz": "Em verdade vos digo, todos terão de renascer da água e da verdade, pois vosso corpo se banha no rio da vida eterna.". 


\title{
THE ABILITY OF WATER TO STORE MEMORY
}

\begin{abstract}
The present work consists of a bibliography review regarding the theme "The water ability to store memory". It is based on two scientific works that describe and prove such ability: Stagnaro (2011) and Montagnier (2011). The aim of this work is to step into the theoretical foundations presented by both authors, thereby elucidating the operation of the retention and memory transmission by water. Also mentioned are some empirical studies from the authors that corroborate the hypothesis that water retains and transmits information, thus introducing also practical elements to the review study. On account of the amount of information presented it was possible to reach a deeper comprehension of the responsible mechanism for this capacity, elucidating and explaining the principle that rules treatments within Naturopathy as florals and homeopathy.
\end{abstract}

Keywords: Water Memory. Energy-information. Florals. Homeopathy. 


\section{REFERÊNCIAS}

BOHM, D. Causality and chance in modern physics. UPA press, 1961.

BOHM, D. Wholeness and the Implicate Order. Ed Routledge, 1980.

BOHM, D. Quantum Theory. Ed Dover Publications New York, 1989.

BOHM, D, PEAT, D. Science, order and creativity. Ed Routledge, 1989.

BOHM, D. A new theory of the relationship of mind and matter. Philosophical Psychology 1990; 3 (2): 271-286.

BOHM, D. Meaning and information archived. Archive today, P. Pylkkänen: The Search for Meaning: The New Spirit in Science and Philosophy, 2011.

EMOTO, M. The Hidden Messages in Water. Hillsboro, OR: Beyond Words Publishing, 2004.

STAGNARO, S. First Water Memory-Information Demonstration through Quantum Biophysical Semeiotics. 2011.

STAGNARO, S. Water Memory-Information containing Muscle Extremely High Energy Frequency: Is the Therapeutic Problem of Chronic Fatigue Syndrome solved? 2011.

STAGNARO, S. Water Memory-Information based Therapy: quick Recovery from Arthrosis-Dependent Backache. www.sisbq.org. 2011.

STAGNARO, S. Glycocalix Quantum-Biophysical-Semeiotic Evaluation plays a Central Role in Demonstration of Water Memory-Information. www.sisbq.org. 2011.

STAGNARO, S. Ruolo del DNA Antennanella Diagnosi Semeiotica Biofisica Quantistica dei Primi due Stadidel Diabete Mellito tipo 2. 2010.

STAGNARO, S. Psychokinetic Diagnostics. Mind, Matterand EnergyInformation. www.scivox.com, 2010

STAGNARO, S. New Renaissance of Medicine. Type 2 Diabetes Mellitus Primary Prevention. Lectio Magistralis, 2010.

STAGNARO, S.. Ruolo del Glicocalicenella Valutazione Semeiotica Biofisica Quantistica dela Sindrome del Fegatolperfunzionante. 2011.

STAGNARO, S. Ruolo del DNA Antennanella Diagnosi Semeiotica Biofisica Quantistica dei Primi due Stadidel Diabete Mellito tipo 2. www.fce.it, 2010.

STAGNARO, S. Psychokinetic Diagnosis and two Dimensions of Time, T1 and T2. www.scivox.com, 2010. 
STAGNARO, S. Psychokinetic Diagnostics. Mind, Matterand EnergyInformation. www.scivox.com, 2010.

STAGNARO, S. New Renaissance of Medicine. Type 2 Diabetes Mellitus Primary Prevention. Lectio Magistralis, 2010.

STAGNARO, S. Ruolo del DNA Antennanella Diagnosi Semeiotica Biofisica Quantistica dei Primi due Stadidel Diabete Mellito tipo 2. www.fce.it, 2010.

STAGNARO, S. Siniscalchi's Sign. Bedside Recognizing in one Second Diabetic Constitution, its Inherited Real Risk, andType 2 Diabetes Mellitus. www.scivox.com, 2010.

STAGNARO, S. Bedside Diagnosing Ovarian Oncological Inherited Real Risk and Cancer. www.scivox.com, 2010.

STAGNARO, S. The Sign of Raggi In Early, and Rapid Bedside Diagnosing Bone Lesion, Including The Mestastasis. www.scivox.com, 2011.

CARAMEL, S. STAGNARO, S. Quantum Biophysical Semeiotics and mitGenome's fractal dimension. Journal of Quantum Biophysical Semeiotics, 2011.

STAGNARO, S. MANZELLI, P. Semeiotica Biofisica Endocrinologica: Meccanica Quantistica e Meccanismi d'Azione Ormonali. www.fce.it, 2007.

STAGNARO, S. Psychokinetic Diagnosis and two Dimensions of Time, T1 and T2. www.scivox.com, 2010.

NERI, M. STAGNARO, S. Introduzione alla Semeiotica Biofisica. II Terreno Oncologico. TravelFactory, Roma, 2004.

NERI, M. STAGNARO, S. Auscultatory Percussion Evaluation of Arteriovenous Anastomoses Dysfunction in early Arteriosclerosis. Acta Med. Medit. 5, 141, 1989.

MONTAGNIER, L. AISSA, J. DEL GIUDICE, E. LAVALLEE, C. TEDESCHI, A. DNA waves and water. J PhysConf Ser, 2011.

BORDEAUX S. O Evangelho Essênio da Paz. Pensamento, 1997. 